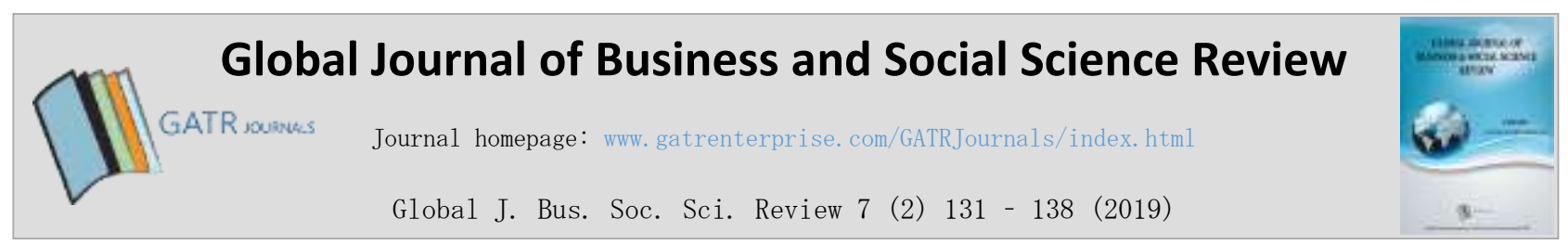

\title{
Public Sector Integrity Violations
}

\author{
Afzal Izzaz Zahari, ${ }^{1} *$ Jamaliah Said ${ }^{2}$ \\ 1,2 Accounting Research Institute, University Teknologi MARA, Shah Alam, Malaysia
}

\begin{abstract}
Objective - Integrity violations can result in small or large financial losses for a community or organisation. These economic losses can be the result of small actions, such as laziness or no determination of work ethics, or large losses, such as corruption practices that can cause an organisation to lose large amounts of money and suffer damage to their reputation. The study will assess the levels of public sector integrity violations among Malaysian government employees.

Methodology/Technique - Previous studies have shown that serious integrity violations, such as fraud, result in major economic loss to a country. This paper explores the perceptions of 616 Malaysian government civil servants who were surveyed regarding matters of integrity violations in their working environment. Surveys were distributed using mail and online distribution formats. The level of integrity violations within the respondent's organisations were evaluated as weak, mild or strong.

Finding - The results indicate that employees in Malaysia are focused on their personal and family relationships despite the fact that this is considered as integrity violations within their organisation.

Novelty - This research provides an overview of the current stage of Malaysian integrity violations and demonstrates the need for improvement in this area. The research also provides valuable insight to managers to improve their control over the organisation.
\end{abstract}

Type of Paper: Empirical

Keywords: Government; Integrity Violations; Malaysia; and Public Sector.

Reference to this paper should be made as follows: Zahari, A. I.; Said, J. (2019). Public Sector Integrity Violations, Global J. Bus. Soc. Sci. Review 7 (2): 131 - 138. https://doi.org/10.35609/gjbssr.2019.7.2(4)

JEL Classification: D23, D73

\section{Introduction}

Governments are amongst the largest organizations in the world (OECD, 2017). Citizens are the main stakeholders for the government and the tax they pay is used in the delivery of designated objectives and goals promised by the elected parties. There are always issues in maintaining a desirable amount of performance from public sector employees. The Malaysian government employs the highest number of public sector employees, with a total of 1.6 million employees recorded in 2017 (Kannan, 2017).

\footnotetext{
* Paper Info: Revised: March 19, 2019

Accepted: June 23, 2019

* Corresponding author: Afzal Izzaz Zahari

E-mail: afzalizzaz@gmail.com

Affiliation: Accounting Research Institute, University Teknologi MARA, Shah Alam, Malaysia
} 
This large workforce makes government organizations increasingly vulnerable to corruption (Goel \& Nelson, 1998). Corruption is considered as strong integrity violations within an organization. Integrity violations often lead to economic loss, of which the stakeholders, in the case of the government the citizens, are directly affected.

\section{Literature Review}

The concept of integrity violation stems from the values of integrity and violation. Integrity is the act of conforming to values and norms to which an individual follows strong ethical values within themselves (Huberts, 2018). Integrity violation is the act of violation towards these values such as honesty and truthfulness. Employees who commit integrity violations not only violate their integrity, they are also violating the ethical values and refusing to follow the expected social norms of the society.

There is a vast body of research on integrity violations. The concept was first introduced in 1998 in a study involving observation of public sector employees (Huberts, 1998). Many studies have followed suit engaging various parties and observing the various effects of integrity violations on organizations and employees (Graaf, 2010; Graaf, Huberts, \& Strüwer, 2017; Huberts, Kaptein, \& Lasthuizen, 2007; Huberts \& Lasthuizen, 2014; Lasthuizen, Huberts, \& Heres, 2011). Initially, there were nine types of integrity violation covering the areas of fraud, corruption, receiving gifts, side activities, misuse of information, discrimination, misuse of power, abuse of resources and crime (Huberts, 1998). Further studies have expanded the areas of integrity violation to include conflict of interest through gifts, conflict of interest through side-line activities, abuse of power, manipulation of information, indecent treatment of colleagues, waste and misconduct in private time.

\subsection{Strength of Integrity Violations}

There are three types of integrity violation: weak, mild and strong. Weak integrity violations are acts of deviant behaviors such as falsely reporting in sick or procrastinating towards assigned duties (Grund \& Fries, 2018; Wessel, Bradley, \& Hood, 2019). Mild integrity violations focus on things such as conducting side activities within the organization (for example, conducting errands for groceries or paying the bills during official working hours) (Graaf et. al., 2017; Kolthoff, Huberts, \& Heuvel, 2007). Strong integrity violations are related to fraud and corruption (Graaf et. al., 2017).

\section{Research Methodology}

The components of integrity violations are gauged based on the strength of the integrity violation experienced by the employees of the organization (Graaf, 2010; Graaf et. al., 2017; Huberts et. al., 2007; Huberts \& Lasthuizen, 2014; Lasthuizen et. al., 2011). Acts of strong integrity violations such as corruption, are observed through activities related to graft, bribery, and embezzlement (Kolthoff, Erakovich, \& Lasthuizen, 2010). The dimensions and items of integrity violations are summarized in the following table:

Table 1. Measurement of Integrity Violations

\begin{tabular}{|c|c|c|}
\hline Type & & Description \\
\hline \multicolumn{3}{|c|}{ Integrity Violation Type 1} \\
\hline \multirow[t]{5}{*}{ Weak } & A1 & There are actions of racial discriminations amongst co-workers \\
\hline & $\mathrm{A} 2$ & There are gender discrimination between male and female counterparts \\
\hline & A3 & There is sexual harassments occurring in my organisation \\
\hline & A4 & There are occurrences of bullying in the organisation \\
\hline & A5 & There are unjustifiable claims on receipts from the employees \\
\hline
\end{tabular}

Global J. Bus. Soc. Sci. Review 7 (2) $131-138$ (2019) 
A6

A7

A8

People reporting in sick in order to skip work

$7 \quad$ People are generally lazy to do their work and not give their full commitment

Co-workers dating each other whether in the same or different department of the organisation

\begin{tabular}{lll}
\hline Integrity Violation Type 2 \\
\hline Mild & B1 & Conducting special favours for family and friends \\
B2 & Receiving gifts with a substantial monetary value (RM 50) \\
B3 & Receiving gifts with large amounts of monetary value (RM 1000) \\
B4 & Conducting personal business during working hours \\
B5 & $\begin{array}{l}\text { Going on breaks during working hours besides the designated period } \\
\text { Conducting personal family affairs during working hours besides the } \\
\text { B6 }\end{array}$ \\
& designated period \\
B7 & Falsely conducting fraudulent transaction such as clocking in work for friends \\
& or co-workers \\
B8 & Being not available after reporting for work and missing from the organisation \\
\hline Integrity Violation Type 3 & Acceptance of bribes \\
\hline Strong & C1 & Offering of bribes \\
C2 & Abuse of power \\
C3 & Using organisational resources for personal benefits \\
C4 & Conducting personal work during working hours \\
C5 & Using office resources during working hours \\
C6 & Personally taking home office resources for personal use \\
C7 & Using organisations funds without proper process \\
C8 & Falsely claiming transactions \\
C9
\end{tabular}

\subsection{Sample and Data Collection}

There is a total of 561 federal and state government departments identified throughout this study. The constructs of a these organizations can be in the form of ministries, departments, agencies, commissions, sections, biros, institutions, foundations and government linked organizations related to the data intended for the study (Department of Information Malaysia, 2017). The target employees are employees holding positions of authority or persons in charge within their organizations including heads of directors, state secretaries or heads of department.

Table 2. Summary of Respondents

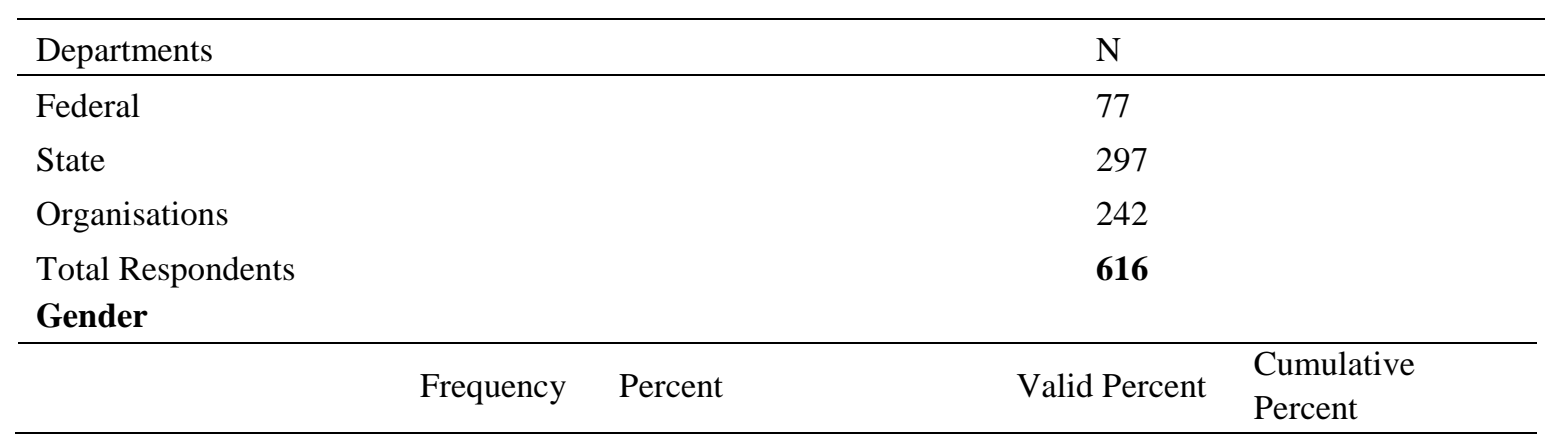




\begin{tabular}{lllll} 
Female & 342 & 55.5 & 55.5 & 55.5 \\
Male & 265 & 43.0 & 43.0 & 98.5 \\
Others & 9 & 1.5 & 1.5 & 100.0 \\
$\begin{array}{l}\text { Total } \\
\text { Age }\end{array}$ & 616 & 100.0 & 100.0 & \\
\hline & & & & \\
\hline Frequency & Percent & Valid Percent & $\begin{array}{l}\text { Cumulative } \\
\text { Percent }\end{array}$ \\
\hline 20-30 Years & 97 & 15.7 & 15.7 & 15.7 \\
$31-40$ Years & 313 & 50.8 & 50.8 & 66.5 \\
$41-50$ Years & 145 & 23.5 & 23.5 & 90.0 \\
51 and above & 56 & 9.1 & 9.1 & 99.1 \\
Others & 5 & 0.8 & 0.8 & 100.0 \\
Total & 616 & 100.0 & 100.0 & \\
Years of service & & & & \\
\hline & Frequency & Percent & Valid Percent & Cumulative \\
& 108 & 17.5 & 17.5 & 17.5 \\
\hline Less than 5 years & 178 & 28.9 & 28.9 & 46.4 \\
6 to 10 years & 154 & 25.0 & 25.0 & 71.4 \\
11 to 15 years & 174 & 28.2 & 28.2 & 99.6 \\
More than 15 years & 2 & 0.3 & 0.3 & 100.0 \\
Others & 616 & 100.0 & 100.0 & \\
Total & & &
\end{tabular}

A seven-point interval scale was used ranging from 1 (strongly disagree) to 7 (strongly agree). The participants were assured that their responses are confidential and that they would not be identified individually. Each of the departments was provided with two copies of the questionnaire. The study also uses an online questionnaire survey to the government departments.

\section{Results}

The Kaiser-Meyer-Olkin (KMO) test was conducted in order to determine if the data was appropriate for factor analysis. The value of the KMO sample of adequacy was 0.961 meaning that data analysed through factor analysis will be quite informative (Hair, Anderson, Tatham, \& Black, 2010). The Bartlett's test of sphericity shows that the data is statistically significant $(\mathrm{p}<0.001)$. The data was then analysed using the Statistical Package for Social Science, version 24 (SPSS).

The study used principal component analysis and varimax rotations. The factor analysis generated $63.8 \%$ of the total variance explained. This conforms to the specification that the eigenvalue's should be greater than 1 and with $60 \%$ of the total variance explained (Field, 2013). The factor loadings were ordered according to their coefficients. The following table shows the results of the factor loading analysis.

Table 3. Component Matrix

\begin{tabular}{llll}
\hline & & Component & \\
\hline Factors & 1 & 2 & 3 \\
\hline A1 & .770 & -.452 & \\
A2 & .770 & -.457 & \\
A3 & .772 & -.409 & \\
A4 & .784 & -.339
\end{tabular}

Global J. Bus. Soc. Sci. Review 7 (2) $131-138$ (2019) 


$\begin{array}{llll}\text { A5 } & .837 & & .326 \\ \text { A6 } & .821 & & .384 \\ \text { A7 } & .746 & & .436 \\ \text { A8 } & .753 & & .342 \\ \text { B1 } & .654 & & \\ \text { B2 } & .739 & & -.355 \\ \text { B3 } & .746 & .463 & \\ \text { B4 } & .810 & .509 & \\ \text { B5 } & .726 & & \\ \text { B6 } & .690 & & -.332 \\ \text { B7 } & .794 & & -.346 \\ \text { B8 } & .785 & & \\ \text { C1 } & .880 & & \\ \text { C2 } & .874 & & \\ \text { C3 } & .883 & & \\ \text { C4 } & .874 & & \\ \text { C5 } & .859 & & \\ \text { C6 } & .808 & & \\ \text { C7 } & .839 & & \\ \text { C8 } & .848 & & \\ \text { C9 } & .855 & & \end{array}$

The three components of integrity violations within the component matrix indicate that each of the factor loading values holds weight in terms of the results. The first component covers all of the integrity violations conducted by employees. The second component relates to integrity violations conducted by the individual through the abuse of organizational resources. The third component of integrity violations relates to the conduct such as bribery and corruption.

The following table shows the mean score of the highest and lowest values towards integrity violations. The highest value is conducting family affairs such as fetching kids from school, visiting sick friends and buying household groceries. The lowest is whereby the majority of the government employees know that accepting bribes for faster service is an integrity violation.

Table 4. Highest and Lowest Mean Values

\begin{tabular}{|c|c|}
\hline Description & Mean \\
\hline Highest & \\
\hline $\begin{array}{l}\text { Conducting personal family affairs during working hours besides the } \\
\text { designated period }\end{array}$ & 3.69 \\
\hline Lowest & \\
\hline $\begin{array}{l}\text { Accepting bribes (money or favours) for delivering better service is } \\
\text { common in the organisation }\end{array}$ & 2.04 \\
\hline
\end{tabular}

\subsection{International Comparisons}

Global public sectors are always facing the issue of integrity violations. For example, recent studies in the Netherlands shows that $28 \%$ of 7,315 Dutch personnel reported suspicion of integrity violation occurring in their organization (Graaf et. al., 2017) despite the fact that the Netherlands has the world ranking of number 8 in the Corruption Perception Index (CPI) 2018 (Transparency International, 2018). 
The following table shows the comparison of the mean scores of bribery, receiving small gifts and large gifts in the United States, Netherlands, Serbia and Montenegro (Kolthoff et. al., 2010). This data is based on public managers and employees within local authorities.

Table 5. Mean Comparisons

\begin{tabular}{lllll}
\hline CPI Ranking in 2018 & Country & Bribery & Small gifts & Large gifts \\
\hline 61 & Malaysia & 2.06 & 2.43 & 2.36 \\
\hline CPI Ranking in 2010 & & & & \\
\hline 22 & USA & 0.27 & 2.07 & 0.62 \\
7 & The Netherlands & 0.36 & 1.79 & 0.18 \\
78 & Serbia & 0.45 & 1.36 & 0.91 \\
69 & Montenegro & 0.95 & 2.07 & 1.51
\end{tabular}

Note: Mean scores are adjusted to the scale range of 1, strongly disagree to 7, strongly agree

The data was obtained in 2010 as this is the only data available for international comparisons (Kolthoff et. al., 2010). These results show that there remains room for improvement for Malaysia in terms of improving integrity in the public sector. The identified weakness in these integrity violations provides opportunities to designing a better roadmap for Malaysian integrity.

\section{Conclusion}

The data indicates that there remains room for improvement in Malaysia. The assessment of the project made through a third party such as a University Institute has made it possible to obtain such results. Official investigations may incur different results. This project is distinguishable from other organizational reports, for example, Transparency International uses different parameters of evaluation (Beddow, 2017). This project is taken from the viewpoint of current Malaysian government employees. The data obtained in this study has provided an improved insight on integrity violations among Malaysian public sector employees and can be used to generate reliable recommendations for the improvement of integrity among those organizations.

The findings of this study also show that conducting family affairs during working hours is very strongly related to the culture maintained by Malaysian citizens (Kennedy \& Mansor, 2000). They care for other people and their family usually takes precedence over official work matters. Although this may be considered as an act of integrity violations, the importance of personal relationships is a national dilemma for employees in Malaysia.

The aim of this study is to assist in moving Malaysia forward in terms of achieving higher levels of ethical values and integrity. Future studies may evaluate results on a yearly basis. Further, more data is needed on the highest violations so that these can be eliminated. This study has shown that all of the items used to assess integrity violations are relevant factors of assessment. The findings of this study provide feasible indicators for evaluating acts of integrity violation within an organization. The data analysis has revealed the factors influencing integrity violations and has highlighted practicable solutions to reduce the prevalence of integrity violations.

\section{Recommendations}

Having goals or targets is necessary for government employees. Previous studies have shown that having proper motivations will improve employee efficiency (Grund \& Fries, 2018). That study states that when 
employees have proper motivation in their work, such as having achievable goals and targets, they will perform better. Hence, the authors of this study recommend the implantation of department and personnel targets on a quarterly basis. Current systems should also be improved (HRMIS 2.0) in order to align the employees with their objectives (HRMIS is the Human Resource Management Information System for Government employees of Malaysia). Though the current system uses a mobile application for phone users, the integration of department and individual objectives may foster better efficiency.

\section{Acknowledgement}

We are indebted to the Institute of Graduate Studies (UiTM), Malaysian Institute of Integrity (IIM) and the Accounting Research Institute (ARI,UiTM) for providing the support needed for this project. We appreciate the reviews and comments made by academicians on earlier drafts of this paper. Thank you to the government agencies, organizations and commissions that participated in the project.

\section{References}

Beddow, R. (2017). Corruption Perceptions Index. Transparency International, 107-114. https://doi.org/978-3-943497$18-2$

Department of Information Malaysia. (2017). Senarai Jabatan atau Agensi Kerajaan Persekutuan. Retrieved May 25, 2017, from http://pmr.penerangan.gov.my/index.php/maklumat-kenegaraan/12071-senarai-jabatanagensi-kerajaanpersekutuan.html

Field, A. (2013). Discovering Statistics Using SPSS. Sage publications (Vol. 3). SAGE Publications Limited. https://doi.org/10.1111/insr.12011_21

Goel, R. K., \& Nelson, M. A. (1998). Corruption and Government Size: A disaggregated analysis. Public Choice, 97, 107-120. https://doi.org/10.1023/A:1004900603583

Graaf, G. de. (2010). A Report On Reporting: Why Peers Report Integrity and Law Violations in Public Organizations. Public Administration Review, 70(5), 767-779. https://doi.org/http://dx.doi.org/10.1111/j.1540-6210.2010.02204.x

Graaf, G. de, Huberts, L., \& Strüwer, T. (2017). Integrity Violations and Corruption in Western Public Governance: Empirical Evidence and Reflection from the Netherlands. Public Integrity, 0(0), 1-19. https://doi.org/10.1080/10999922.2017.1350796

Grund, A., \& Fries, S. (2018). Understanding Procrastination: A motivational approach. Personality and Individual Differences, 121(March 2017), 120-130. https://doi.org/10.1016/j.paid.2017.09.035

Hair, J. F., Anderson, R. E., Tatham, R. L., \& Black, W. C. (2010). Multivariate Data Analysis: A global perspective. Upper Saddle River (7th Editio). New Jersey: Prentice Hall.

Huberts, L. (1998). What can be Done against Public Corruption and Fraud: Expert views on strategies to protect public integrity. Crime, Law and Social Change, 29(188801), 209-224. https://doi.org/Doi 10.1023/A: 1008348803253

Huberts, L. (2018). Integrity: What it is and Why it is Important. Public Integrity. https://doi.org/10.1080/10999922.2018.1477404

Huberts, L., Kaptein, M., \& Lasthuizen, K. (2007). A Study of The Impact of Three Leadership Styles on Integrity Violations Committed by Police Officers. Policing: An International Journal of Police Strategies \& Management, 30(4), 587-607. https://doi.org/10.1108/13639510710833884

Huberts, L., \& Lasthuizen, K. (2014). The Integrity of Governance. (R. Fouchet \& T. Brandsen, Eds.), Palgrave Macmillan, London (First Edit). France.

Kannan, H. K. (2017). Johari denies saying number of civil servants have led to decreased productivity. New Straits Times Online, p. 1. Retrieved from https://www.nst.com.my/news/2017/02/213350/johari-denies-saying-number-civilservants-have-led-decreased-productivity

Kennedy, J., \& Mansor, N. (2000). Malaysian Culture and The Leadership of Organisations: A GLOBE study. Malaysian Management Review, 35(2), 42-53.

Kolthoff, E., Erakovich, R., \& Lasthuizen, K. (2010). Comparative Analysis of Ethical Leadership and Ethical Culture in Local Government. International Journal of Public Sector Management, 23(7), 596-612. https://doi.org/10.1108/09513551011078879 
Kolthoff, E., Huberts, L., \& Heuvel, H. van den. (2007). The Ethics of New Public Management : Is Integrity at Stake? Public Administration Quarterly, 30(4), 399-439. Retrieved from http://www.publicservices.ac.uk/wpcontent/uploads/nig_ethics_integrity.pdf

Lasthuizen, K., Huberts, L., \& Heres, L. (2011). How to Measure Integrity Violations: Towards a Validated Typology of Unethical Behavior. Public Management Review, 13(3), 383-408. https://doi.org/10.1080/14719037.2011.553267

OECD. (2017). Government at a Glance: 2017 edition. Retrieved January 26, 2019, from https://stats.oecd.org/Index.aspx?QueryId=78408

Transparency International. (2018). Corruption Perception Index 2018. Retrieved from https://www.transparency.org/cpi2018

Wessel, J., Bradley, G. L., \& Hood, M. (2019). Comparing Effects of Active and Passive Procrastination: A field study of behavioral delay. Personality and Individual Differences, 139(July 2018), 152-157. https://doi.org/10.1016/j.paid.2018.11.020 